\title{
BI-LAYER DIAPHRAGM WALLS: STRUCTURAL AND SECTIONAL ANALYSIS
}

\author{
Luis SEGURA-CASTILLO ${ }^{\mathrm{a}, \mathrm{b}}$, Antonio AGUADO ${ }^{\mathrm{a}}$, Albert DE LA FUENTE ANTEQUERA ${ }^{\mathrm{a}}$, \\ Alejandro JOSA ${ }^{\mathrm{c}}$ \\ ${ }^{a}$ Technical University of Catalonia-Barcelona Tech (UPC), School of Civil Engineering (ETSECCPB), \\ C/Jordi Girona 1-3 Modul C1, Barcelona 08034, Spain \\ ${ }^{b}$ Instituto de Estructuras y Transporte, Facultad de Ingeniería, Universidad de la República (UdelaR), \\ J. Herrera y Reissig 565, 11300, Montevideo, Uruguay \\ ${ }^{c}$ Department of Geotechnical Engineering and Geosciences, School of Civil Engineering, Universitat Politècnica \\ de Catalunya-Barcelona Tech (UPC), C/Jordi Girona 1-3 Modul D2, 08034 Barcelona, Spain
}

Received 17 Mar 2013; accepted 18 Jul 2013

\begin{abstract}
The bi-layer diaphragm wall, a new slurry wall type designed to cope with the problem of watertightness is studied in this paper. These walls consist of two bonded concrete layers, the first, a conventional Reinforced Concrete (RC) diaphragm wall, and the second, a Sprayed Steel Fibre Reinforced Concrete (SFRC). The main objective of this paper is to analyze the structural and sectional behaviour of these walls. A study in the form of an uncoupled structuralsection analysis based on various hypothetical cases of bi-layer diaphragm walls was performed to fulfil the objective. It is concluded that there exists a potential of reduction in the reinforcement of the RC layer through the structural use of the SFRC layer. However, when the reduction is quantified, even though a reduction of between $3.2 \%$ and $1.7 \%$ in the $\mathrm{RC}$ reinforcement is confirmed, it appears insufficient to offer a cost-effective solution. Nonetheless, the system becomes a promising solution when particular conditions are taken into account, such as basement space limitations.
\end{abstract}

Keywords: waterproof, diaphragm walls, fibre concrete, sprayed concrete, numerical analysis, FEM, PLAXIS.

\section{Introduction}

A widespread problem associated with diaphragm wall construction is the occurrence of leakage whenever erected in water-bearing ground. There are no techniques to make diaphragm walls fully watertight, so a variety of alternatives, all of which with different drawbacks, have been developed to cope with the leakage problem (Puller 1994). The waterproof system in these solutions is added to the wall after their construction is complete, so it is not an integral part of the structure of the walls.

Considering the aforementioned points, one conceivable solution would be a waterproof layer that also assumes a structural function. The bi-layer diaphragm wall, a new slurry wall type, designed to cope with the problem of watertightness in these types of walls has previously been presented by Segura-Castillo et al. (2013). These walls consist of two bonded concrete layers poured and then sprayed, in separate stages. The first is a conventional Reinforced Concrete (RC) diaphragm wall. Once this wall attains the necessary strength, soil within the perimeter is excavated and removed, and the second layer, this time of Sprayed Steel Fibre Reinforced Concrete (SFRC) and a waterproof additive, is applied.
This paper is part of an experimental and theoretical study on bi-layer diaphragm walls, which has been structured into four main areas: a) Structural level analysis; b) Sectional level analysis; c) Bonding between layers; and d) General design and optimization. Of these, the structural level behaviour was partially reported in Segura-Castillo et al. (2013), and the bond analysis in Segura-Castillo and Aguado (2012).

The main objective of this paper is to analyze the structural and sectional behaviour of the bi-layer diaphragm walls. The overall design method is presented. With it, the contribution of each layer is quantified, placing special emphasis on the SFRC layer contribution.

\section{Methodology}

A study in the form of an uncoupled structural-section analysis based on the hypothetical case of various bi-layer diaphragm walls was performed to fulfil our objectives.

A 2D Finite Element Model (FEM) was selected to analyze the structural behaviour. A numerical rather than a simplified model is necessary, as the constructive sequence is considered (Carrubba, Colonna 2000), which includes the cross-section changes that take place when

Corresponding author: Luis Segura-Castillo

E-mail: lsegura@fing.edu.uy 
the SFRC is sprayed, together with general wall and soil properties. The literature contains many studies that utilize these models to analyze ground movements caused by deep excavations, due to their importance in the prediction of possible damage to adjacent buildings during excavation process (e.g. Hsiung 2009; Khoiri, Ou 2013; Kung et al. 2007; Kung 2009). On the other hand, fewer studies (e.g. Carrubba, Colonna 2000; Costa et al. 2007; Ou, Lai 1994) have evaluated the forces and stresses produced on the walls.

It should be mentioned that use of the elasticperfectly plastic "Mohr-Coulomb" model means that the soil has to be discretized into several horizontal layers and its elastic properties have to be changed as the depth increases, before the model responds to any increase in the soil modulus of elasticity, due to increased vertical pressure (Khoiri, Ou 2013). The hardening soil model (HS) (Schanz et al. 1999) was therefore chosen, as it models the entire ground in the study with only one set of parameters.

The numerical simulation of the mechanical behaviour of the composite sections of the wall was performed with the model "Analysis of Evolutionary Sections" (AES) (de la Fuente et al. 2012a). This model simulates the non-linear response of sections built with different materials (concrete and steel) and the structural contribution of the SFRC, when subjected to tension. In the AES model, the concrete sections are discretized in layers of constant thickness (Fig. 1a), whereas steel rebars are simulated as concentrated-area elements.

In this study, the procedure to design the reinforcement of the concrete wall followed the basic design principles for traditional reinforced concrete presented in BS EN 1992-1-1:2004 (2004). According to these hypotheses, the ultimate bending moment $\left(M_{U}\right)$ is calculated and compared with the maximum design bending moment $\left(M_{d}\right)$, calculated by the structural analysis, for the most unfavourable construction stage and for each kind of section.

The compressive behaviour of the concrete (Fig. 1b) was simulated, on the one hand, by considering the constitutive law proposed in EC-2 (EN 2004). On the other hand, the tensile response of the SFRC was simulated through constitutive law $\sigma_{c}-\varepsilon_{c}$, as suggested in RILEM (2003). Finally, the mechanical performance of the steel bars was simulated with the bilinear diagram presented in Figure 1c.

In addition to the internal equilibrium conditions, the following hypotheses are also considered: (1) the sections remain plane before the application of the external forces or after imposing fixed strains; (2) failure of the composite section is achieved when there is either excessive compressive strain in the upper concrete layer $\left(\varepsilon_{R C, t}=-3.5 \%\right)$ and/or excessive elongational strain in the tensioned steel bars $\left(\varepsilon_{s, i}=10.0 \%\right)$; and (3) a perfect bond between the concrete and the rebars, as well as between the RC and the SFRC layers. Regarding the latter, it has to be mentioned that the suitability of this assumption has previously been studied in Segura-Castillo and Aguado (2012).

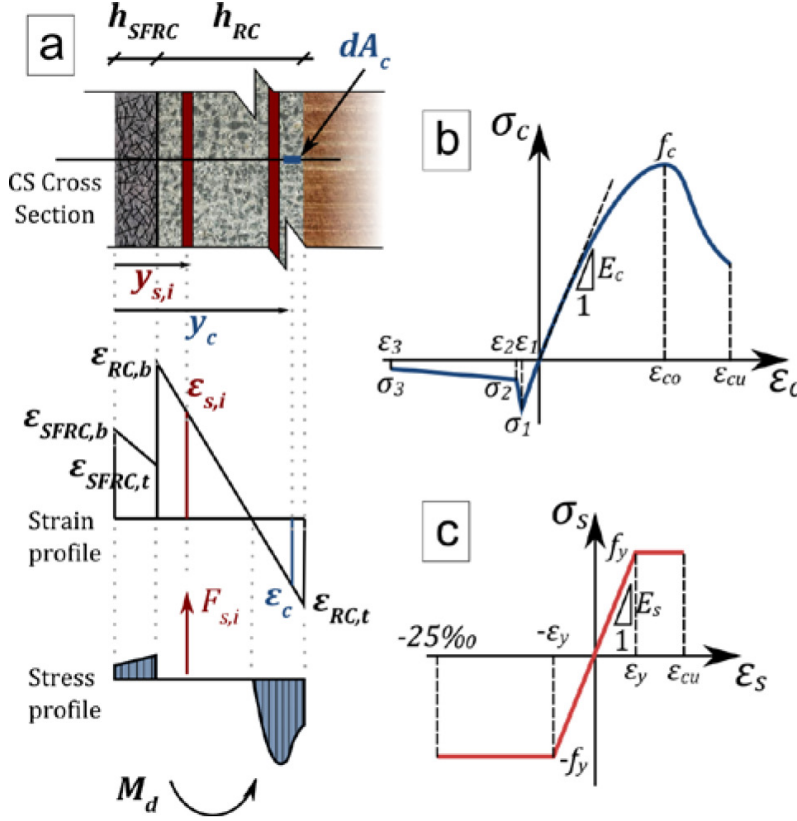

Fig. 1. Sectional discretization (a); SFRC (b); and steel bar constitutive equations (c)

\section{Characteristics of the walls}

\subsection{Geometry and construction sequence}

This study is based on the hypothetical case of the construction of walls designed for use in a four level basement. The comparison considers one conventional diaphragm wall, referred as the mono-layer wall (ML) for the sake of clarity, and two bi-layer walls (BL), differentiated only by their thicknesses (all other properties remaining constant):

- $M L_{60}$ : Conventional RC diaphragm wall of $60 \mathrm{~cm}$ thickness;

- $B L_{60+10}$ : Bi-layer RC wall with a thickness of $60 \mathrm{~cm}$ onto which a $10 \mathrm{~cm}$ thick SFRC layer is sprayed;

- $B L_{55+10}$ : Bi-layer RC wall with a thickness of $55 \mathrm{~cm}$ onto which a $10 \mathrm{~cm}$ thick SFRC layer is sprayed.

The general characteristics of the walls used in this study are similar to those used by Carrubba and Colonna (2000), in order to contrast our results with others from the technical literature. Apart from some minor differences, a major difference is the increase in the penetration depth of the walls. This change is because the one in the reference is below the usual range for this depth of excavation (Long 2001).

The selected diaphragm wall was $20.0 \mathrm{~m}$ high and required an excavation depth of $12.5 \mathrm{~m}$ (with a $7.5 \mathrm{~m}$ embedded footing), as illustrated in Figure 2a. During the excavation process, the wall was supported by up to 4 rows of ground anchors vertically spaced at $3.0 \mathrm{~m}$ and horizontally spaced at $5.0 \mathrm{~m}$ in the two upper rows: Superior Anchorages (S.A.); and at $2.5 \mathrm{~m}$ in the two lower rows: Inferior Anchorages (I.A.). 
The "bottom-up" construction sequence of the three alternatives is detailed in Table 1. The stages are divided in 5 groups, the first 4 of which correspond to the Excavation (Exc.) works required for each of the 4 Anchorage (Anc.) installations. In the fifth group, apart from a small final excavation, the slabs are built and the 4 anchorages removed (Anc.Out).

The soil extraction process for the $B L_{60+10}$ and $B L_{55+10}$ bi-layers walls is sub-divided into shorter stages. In addition, after each partial excavation stage, the SFRC layer is Sprayed (Spray.), from the last sprayed level to the lower excavated level, changing the cross-section from the Simple Section (SS, see Fig. 2b) to the Compound Section (CS, see Fig. 2c) in the sprayed stretch.

\subsection{Material and model characteristics}

The numerical model was calculated on the commercial geotechnical finite-element software package PLAXIS (Brinkgreve 2002). The FEM mesh used is shown in Figure 3. Horizontal fixity was imposed for the vertical boundaries as well as both horizontal and vertical fixities for the bottom boundary, as shown in the same figure. A fine global coarseness was taken for the general mesh (automatically defined by the program), and refined in the vicinity of the wall. A model with a more refined mesh verified that the element size had no significant

Table 1. Construction stages sequence

\begin{tabular}{|c|c|c|c|}
\hline Group & Depth* (m) & $M L_{60}$ & $\begin{array}{c}B L_{60+10} \text { and } \\
B L_{55+10}\end{array}$ \\
\hline \multirow{3}{*}{1} & - & Wall constr. & Wall constr. \\
\hline & 1.75 & Exc.1 & Exc.1 \\
\hline & 1.50 & Anc. 1 & Anc. 1 \\
\hline \multirow{5}{*}{2} & 3.75 & - & Exc.2a \\
\hline & 3.50 & - & Spray.2a \\
\hline & 4.75 & Exc. 2 & Exc.2b \\
\hline & 4.50 & - & Spray.2b \\
\hline & 4.50 & Anc. 2 & Anc. 2 \\
\hline \multirow{5}{*}{3} & 6.75 & - & Exc.3a \\
\hline & 6.50 & - & Spray.3a \\
\hline & 7.75 & Exc.3 & Exc.3b \\
\hline & 7.50 & - & Spray.3b \\
\hline & 7.50 & Anc. 3 & Anc. 3 \\
\hline \multirow{5}{*}{4} & 9.75 & - & Exc.4a \\
\hline & 9.50 & - & Spray.4a \\
\hline & 10.75 & Exc. 4 & Exc.4b \\
\hline & 10.50 & - & Spray.4b \\
\hline & 10.50 & Anc. 4 & Anc. 4 \\
\hline \multirow{4}{*}{5} & 12.50 & Exc.5 & Exc. 5 \\
\hline & 12.25 & - & Spray.5 \\
\hline & - & slabs & slabs \\
\hline & - & Anc.Out & Anc.Out \\
\hline
\end{tabular}

* Excavation base, Anchorage position, or Spraying base, according to the respective stage.

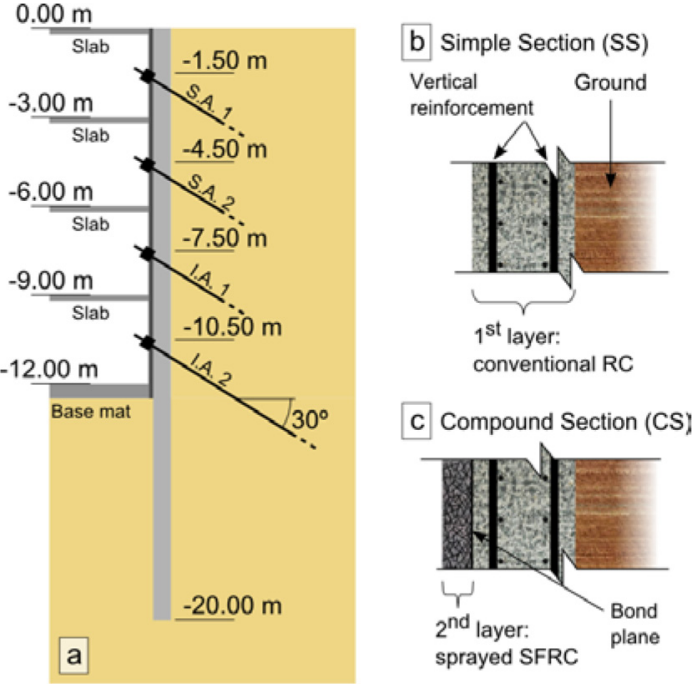

Fig. 2. (a) Model geometry: Anchorages and slabs positions; (b) Simple Section (SS); (c) Compound Section (CS)

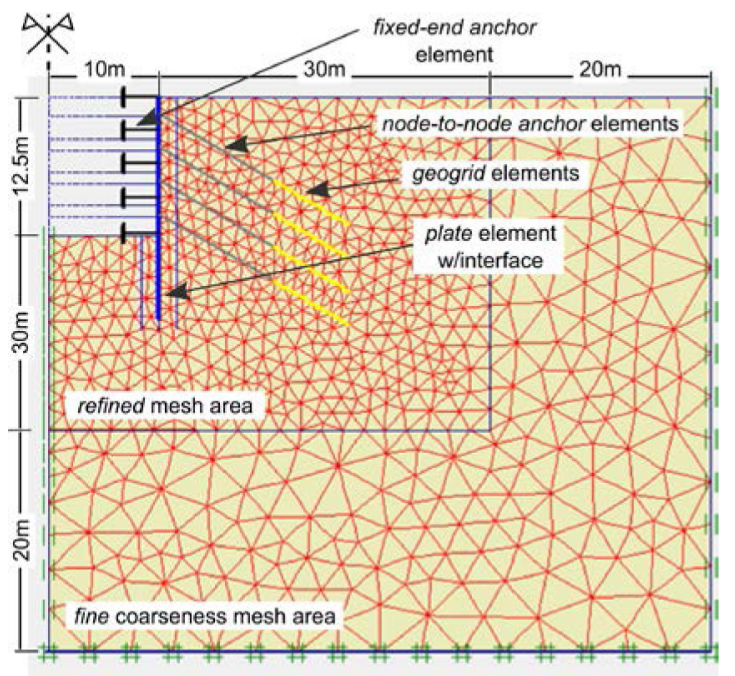

Fig. 3. Finite element model mesh and main elements

effects on the analytical results. Besides, no external loads were considered in the model.

Plate structural elements (linear elastic) were used to model the diaphragm walls, which were considered wished in place (Bryson, Zapata 2012). A compressive strength $f_{c k}=30 \mathrm{MPa}$, a Poisson ratio $v=0.2$, and a specific weight of $24 \mathrm{kN} / \mathrm{m}^{3}$ were considered for the concrete of both layers. Its modulus of elasticity, according to EC-2 (EN 2004), was $E_{c m, 28}=33000 \mathrm{MPa}$.

The flexural $(E I)$ and normal $(E A)$ stiffness values calculated for the SS and the CS cross-sections, are shown in Table 2. All stiffnesses have been reduced by $20 \%$ from the nominal value (uncracked cross-section) to consider the existence of cracks in the wall (Khoiri, Ou 2013). In the FEM model, the self-weight and stiffnesses were updated from the SS to the CS values for the corresponding beam lengths that had been sprayed after each of the spraying stages. As "it is very important that the ratio of EI / EA is not changed" to avoid numerical 
Table 2. Flexural and normal stiffness of the different walls

\begin{tabular}{lcccc}
\hline & & $M L_{60}$ & $B L_{60+10}$ & $B L_{55+10}$ \\
\hline$E I$ & $\mathrm{SS}$ & 475.2 & 475.2 & 366.0 \\
\cline { 2 - 5 }$\left(\mathrm{MN} \cdot \mathrm{m}^{2}\right)$ & $\mathrm{SC}$ & --- & 754.6 & 604.2 \\
\hline$E A$ & $\mathrm{SS}$ & 15840 & 15,840 & 14,520 \\
\cline { 2 - 5 }$(\mathrm{MN})$ & $\mathrm{SC}^{+}$ & --- & 25,153 & 23,967 \\
\hline
\end{tabular}

+ Value calculated to keep the EI/EA ratio unchanged.

inconsistencies (PLAXIS 2010) and our main interest centres on the bending moments, the EA values of the bi-layer were calculated to maintain a constant EI/EA ratio. It can be seen that the flexural stiffness of the CS for both bi-layer alternatives increased by about $60 \%$ in comparison with that of the SS.

The soil elements were 15 -node triangular finite elements under plane strain. A sandy soil was chosen for this analysis, as water filtration problems are more likely in a permeable soil.

The soil parameters and the values used for the selected model correspond to the "Lake sand layer", taken from an experimental case reported in the literature (Hashash et al. 2010). The coefficient of lateral earth pressure at rest $\left(K_{0}\right)$ was automatically estimated by the program using the expression of Jaky (Terzaghi et al. 1996). A total unit weight of $\gamma=20.0 \mathrm{kN} / \mathrm{m}^{3}$ was selected for the soil. Interface elements were set out for the soil in contact with the plate elements (with a strength reduction factor for soil-structure interface of $R_{\text {inter }}=0.66$ (Khoiri, Ou 2013)) and continued $1.0 \mathrm{~m}$ below the bottom end of the walls, as suggested by PLAXIS (2010). A Drained analysis was used, even though the phreatic level was below the model boundaries and therefore no water flow was considered.

The permanent wall supports were modelled with fixed-end anchors. Anormal stiffness of $E A=7.26 \cdot 10^{6} \mathrm{kN} / \mathrm{m}$ (equivalent to a $22 \mathrm{~cm}$ thick massive slab) with an equivalent support length of $10 \mathrm{~m}$ (the length from the walls to the axis of symmetry of the model) was used for the upper slabs. A stiffness of $E A=1.65 \cdot 10^{7} \mathrm{kN} / \mathrm{m}$ (equivalent to a $50 \mathrm{~cm}$ thick massive slab), also with an equivalent support length of $10 \mathrm{~m}$ was used for the bottom slab.

Geogrid structural elements and node-to-node anchor elements were used to model the body and the free length, respectively, of the ground anchors. The following properties were used. Initial tensile load: $50 \mathrm{kN} / \mathrm{m}$ for "S.A. 1 and 2" and $100 \mathrm{kN} / \mathrm{m}$ for "I.A. 1 and 2"; Horizontal distance: $5.0 \mathrm{~m}$ for "S.A. 1 and 2" and $2.5 \mathrm{~m}$ for "I.A. 1 and 2". The rest of the properties are equal for both types of anchorages. Total length: $20 \mathrm{~m}$; Bulb length: $14 \mathrm{~m}$; Cross-section area: $450 \mathrm{~mm}^{2}$; Elastic modulus: $200 \mathrm{KN} / \mathrm{mm}^{2}$; and Angle: $30^{\circ}$.

A fibre content of $25 \mathrm{~kg} / \mathrm{m}^{3}$ was used in the SFRC. The post-cracking behaviour of the SFRC may be defined by the expressions given in de la Fuente et al. (2012b). The nominal cover used for the RC bars was $70 \mathrm{~mm}$.

\section{Structural results}

The displacement plot of the three wall types corresponding to the final stage ("Anc.Out") are shown in Figure 4. The upper part of the plot is enlarged for clarity. In general terms, the displacement of each wall type is similar, with differences in the maximum displacement value of less than $0.8 \mathrm{~mm}(4.6 \%)$, and within the order of magnitude of displacements of the reference case (Carrubba, Colonna 2000).

Displacements at depths of between $-5 \mathrm{~m}$ to $-20 \mathrm{~m}$ of the walls with a RC width of $60 \mathrm{~cm}$ (" $M L_{60}$ " and " $B L_{60+10}$ ") are practically identical. The reduced influence of the second layer is, on the one hand, due to the stiffness of the two types of walls, which are the same at depths of between $-12.5 \mathrm{~m}$ and $-20.0 \mathrm{~m}$. On the other hand, increased stiffness at depths of between $-6.0 \mathrm{~m}$ and $-12.5 \mathrm{~m}$ following spraying of the SFRC layer is noted during the final excavation stages, after most of the soil pressure had been already mobilized.

The displacements of the " $B L_{55+10}$ " wall type are slightly higher than the previous ones. This behaviour, which coincides with data reported in (Segura-Castillo et al. 2013), is due to the fact that the stiffness of the $\mathrm{RC}$ layer determines the overall displacement behaviour.

Larger displacements than in " $\mathrm{ML}_{60}$ " wall at depths of between $0.0 \mathrm{~m}$ and $-5.0 \mathrm{~m}$ can be seen in the "BL $60+10$ " wall. Although it might appear contradictory, this is reasonable because the flexural stiffness of the bilayer wall increases after spraying of the SFRC layer. Therefore, the curvature increase of the bi-layer wall is smaller than in the mono-layer alternative as the bending moment increases. In this instant, as the wall is more restrained in the lower part (at depths of below $-5.0 \mathrm{~m}$ ) owing to the embedded end of the wall and the stiffer

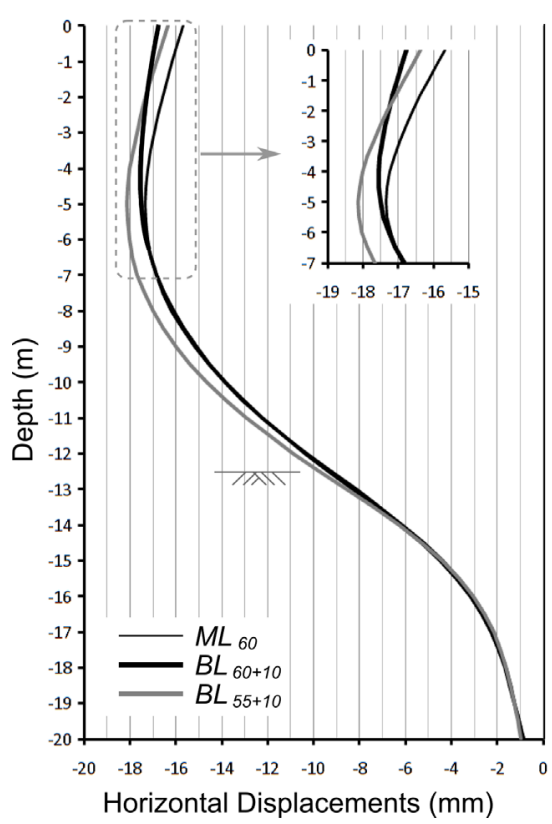

Fig. 4. Wall displacements: "Anc.Out" stage for the three walls 
lower anchors, the upper free end of the wall is dragged outwards at greater extent.

The envelope of flexural design moments $\left(M_{d}\right)$ obtained for all three wall types, for both the SS and for the CS sections, are shown in Figure 5a. A partial factor of $\gamma=1.5$ was applied to the actions of the ground on the wall. The positive moments of the envelope are the same for both kinds of sections. In turn, while there is a single envelope for the negative moments of the mono-layer wall, the envelope is broken down into two envelopes for the bi-layer walls. The envelopes of maximum moment, until the CS was completed (i.e. until the SFRC was sprayed) are shown by a continuous line $\left(M_{d}^{S S}\right)$ and the envelopes where the CS was completed by a dashed line $\left(M_{d}^{C S}\right)$. The way these envelopes were generated is explained below in greater detail. In general terms, the envelopes are qualitatively similar and within the order of magnitude of the reference case (Carrubba, Colonna 2000).

Comparing the bi-layer walls, it can be seen that the " $B L_{60+10}$ " shows larger moments than the " $B L_{55+10}$ " along the whole length of the wall. This is a consequence of the greater stiffness of the RC layer and, therefore, greater stiffness both in the SS and in the CS crosssection.

The " $M L_{60}$ " and " $B L_{60+10 "}$ " wall types show practically identical envelopes in the embedded section of the wall (between depths $-12.5 \mathrm{~m}$ and $-20.0 \mathrm{~m}$ ). In this section, both walls have the same cross-section (i.e. the RC layer) for all the stages. The biggest differences between these wall types was registered in the centre of the walls, between depths $-5.0 \mathrm{~m}$ and $-12.0 \mathrm{~m}$, in which the " $B L_{60+10}$ " envelope was larger. As the SFRC layer is sprayed, the upper stretches become stiffer, diminishing any relative collaboration of the embedded part of the wall.
The bending moments of the " $B L_{60+10}$ " wall type are detailed in Figure 5b, in which light-grey lines indicate the moment of the representative stages of each excavation stage. The interval between the envelopes previously introduced in Figure 5a $\left(M_{d}^{S S}\right.$ and $\left.M_{d}^{C S}\right)$ is highlighted with slanting lines. This area represents the increase in the moments after spraying the SFRC layer (i.e. where the CS cross-section is working).

As stated in Segura-Castillo et al. (2013), the highlighted area represents the potential use of the bi-layer wall, since it is possible to cover these moments with the resistance of the CS section. It can be seen that for the depths where the CS section is present, a significant portion of the bending moments are developed after the SFRC layer has been sprayed. These increases range from $30 \%$ to $269 \%$ at depths of between $-2.5 \mathrm{~m}$ and $-11.0 \mathrm{~m}$, with an average increase of $123 \%$ in the design moment of those depths after the SFRC layer is sprayed.

The value of the area within the SS cross section envelope is represented with a solid bar graph to compare the three wall types, in Figure $5 \mathrm{c}$. The value of the area of the CS cross section (as shown in Fig. 5b) is also plotted (slanting lines). It may be noted that the potential of use of the SFRC layer covers approximately $25 \%$ of the area of moments.

The bending moments plots of the " $B L_{60+10}$ " wall type at depths of between $0.0 \mathrm{~m}$ and $-5.0 \mathrm{~m}$, for the stages from "Exc.2a" to "Spray.2b" are shown in Figure 6. For each plot, dark lines indicate the moments of the stage and light-grey lines indicate the moments of the previous stages. The envelopes of moments already shown in Figure 5 are obtained when the following process explained below is applied to all the stages.

It can be seen that the bending moments of the excavation stage (Fig. 6a) are identical to those of the stage
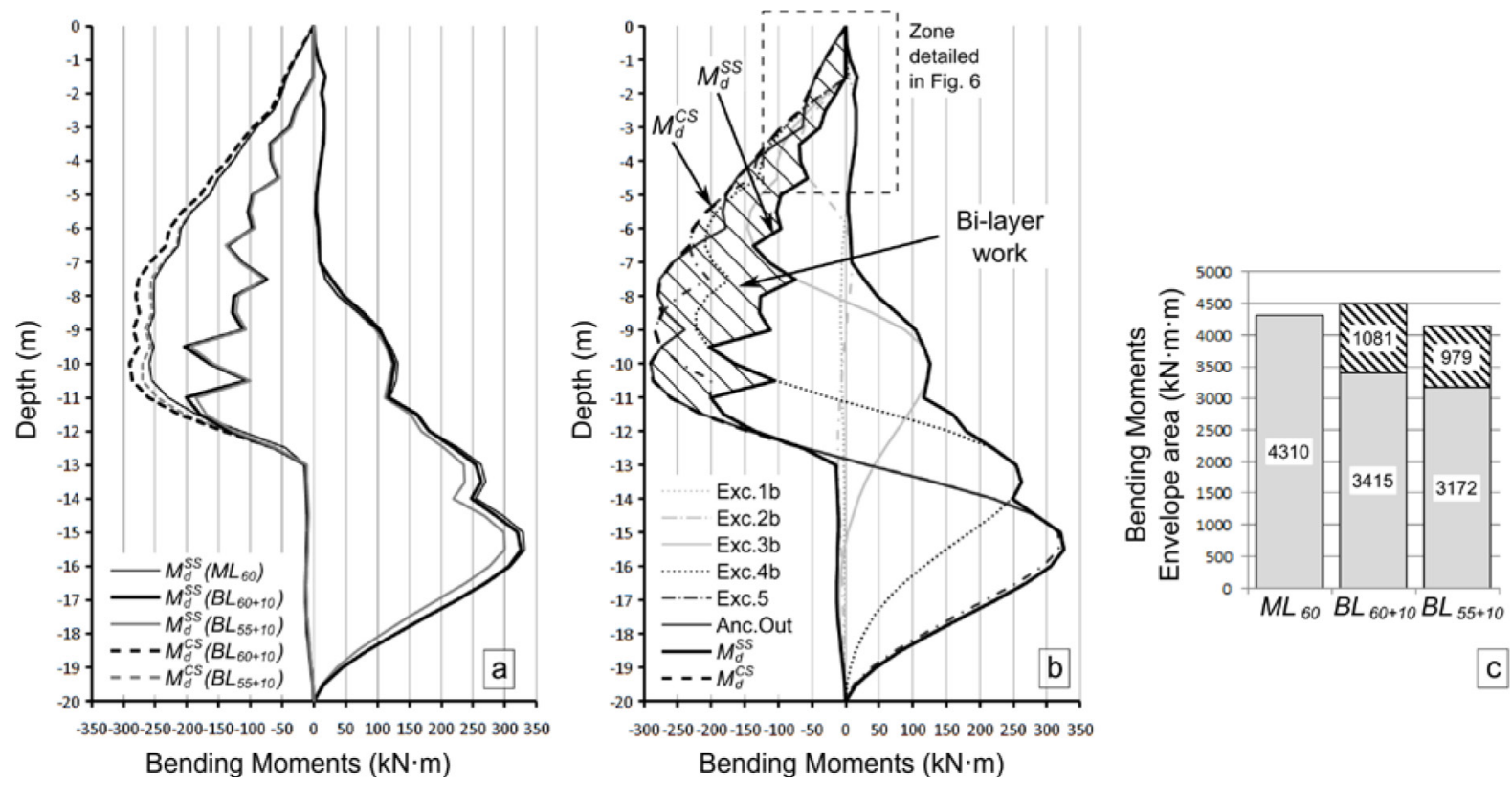

Fig. 5. Bending moments: a) envelopes for the three wall types; b) representative stages and envelopes for the "BL60+10" wall type; c) envelope areas for all three wall types 

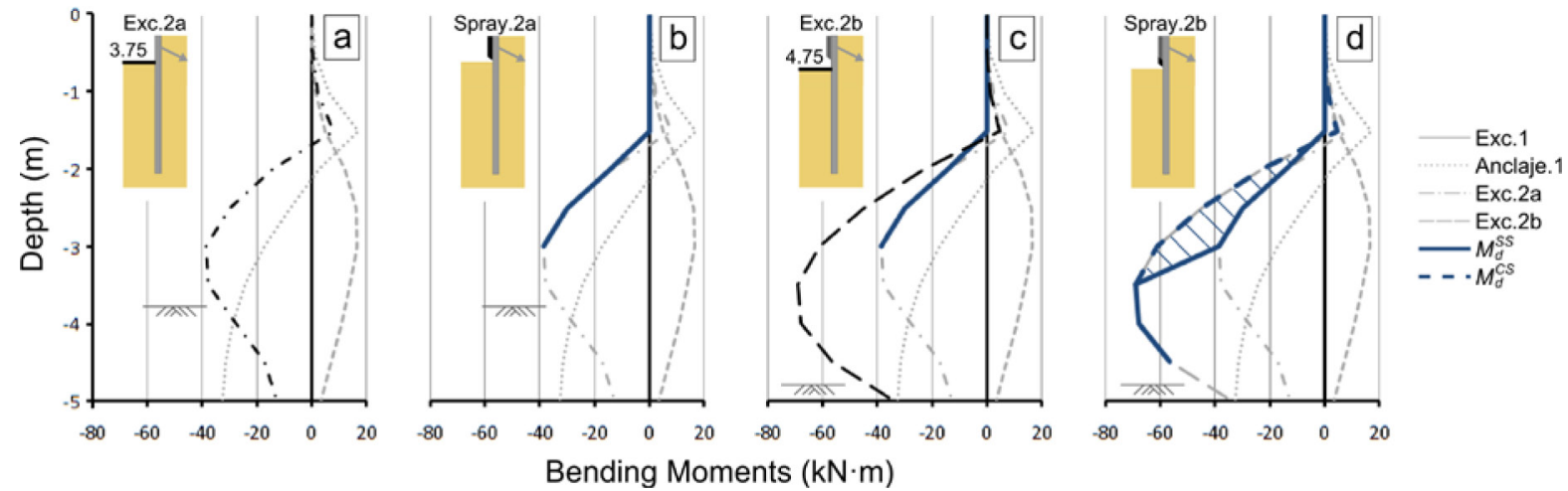

Fig. 6. Diagrams of moments at stages prior to the second anchor installation

where the SFRC is sprayed (Fig. 6b). This is because, immediately after spraying, all the SFRC layer adds is its own-weight, which is considered in the model by updating the weight of the beam element. This implies a small change in the normal stresses of the element and an insignificant change in the bending moments. The external loads on the wall remain constant until a new excavation stage takes place.

The differential time-dependent strains between $\mathrm{RC}$ and SFRC layers are left out of the model, bearing in mind that the RC layer, as a slurry wall, has a high confined water content (before excavation) and that the sprayed SFRC layer, with a waterproofing additive, has a greater capability of withholding moisture.

After the spraying stage, the wall has the CS crosssection at depths of between $0.0 \mathrm{~m}$ and $-3.0 \mathrm{~m}$. Therefore, until this stage is complete, the bending moments are resisted exclusively by the SS cross-section. The envelope of these moments is represented with an unbroken bold line.

The changes in bending moments of stage "Exc.2b" are shown in Figure 6c. The increase in bending moments at depths of between $0.0 \mathrm{~m}$ to $-3.0 \mathrm{~m}$ can now be withheld by the CS cross-section. The maximum moments that develop once the CS cross-section is completed are referred to as $M_{d}^{C S}$, and its envelope is represented with a bold dashed line, as shown in Figure 6d. This figure represents the situation after spraying the second stretch (Spray.2b), in which the two kinds of envelopes may be seen.

\section{Sectional results}

The design criteria set the ultimate moment resistance as equal or greater than the design moment of each cross-section $\left(M_{U} \geq M_{d}\right)$. This particular criterion is used for the dimensioning of the main vertical reinforcement, which accounts for the differences introduced by the various wall types analysed in this study. Therefore, secondary reinforcements (e.g. for transversal stresses or time-dependant effects) are neglected in this study as they are considered the same for all three wall types. The shear force, and its reinforcement, is also neglected as it is not usually a determinant in the design of the walls.
Reinforcement of the RC layer involves: a) a symmetric reinforcement on both sides of the wall with the minimum mechanical reinforcement " $A_{S, \min }$ " (according to the EHE-08 code (CPH 2008)); and b) one extra reinforcement per side of the Wall, one for the positive moments " $A_{s,+}$ ", and another one for the negative ones " $A_{S,-}$ ", to cover the extra moment that the minimum reinforcement does not cover. The addition of both areas " $A_{T}$ " was used in the calculations for cross-sections in which both reinforcements were present. Only tensioned bars were used in the calculation.

Two ultimate moment resistances, whether or not we consider the SFRC layer, were obtained for the bi-

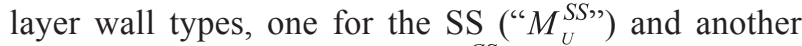

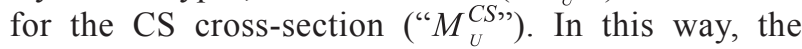
design condition for the bi-layer walls can be differentiated according to the type of section that is active at each instant, establishing that every cross-section must at every instant simultaneously satisfy both relationships given by the following inequalities:

$$
\begin{gathered}
M_{U}^{s S} \geq M_{d}^{s s} ; \\
M_{U}^{C S} \geq M_{d}^{C S} .
\end{gathered}
$$

The values of the reinforcements obtained for the three wall types are shown in Table 3. The following information is given for each alternative: bar diameter " $d$ " and bar spacing " $s$ " expressed in the form " $\phi d / s$ "; the position of the reinforcements " $z$ inf" and " $z$ sup" (Fig. 7) and the ultimate moment resistance of the SS and the CS cross-sections.

The ultimate resistance of the CS cross-section where the positive moment reinforcements were placed was not calculated, since this reinforcement is placed at depths lower than $12.5 \mathrm{~m}$, where there is no second layer. The ultimate moments obtained with the aforementioned reinforcements cover the design moments in the whole wall (Ec. 1 and 2).

The increase in the ultimate moment resistance, given by the contribution of the SFRC layer, ranges from $14.5 \%$ (" $A_{S,-}$ " of the $B L_{55+10}$ wall type) to $21.0 \%$ (" $A_{S, \min }$ " of the $B L_{55+10}$ wall type) in relation to the resistance of the SS cross-section. 
Table 3. Reinforcements and $M_{\mathrm{U}}$ of the different wall types

\begin{tabular}{|c|c|c|c|c|c|}
\hline \multirow{3}{*}{$\begin{array}{l}\text { Wall } \\
\text { Type }\end{array}$} & \multirow[t]{2}{*}{ Reinforcement } & \multicolumn{2}{|c|}{ Position $^{a}$} & \multicolumn{2}{|c|}{$M_{U}$} \\
\hline & & $z^{i n f}$ & $z^{\text {sup }}$ & $M_{U}^{S S}$ & $M_{U}^{C S}$ \\
\hline & {$[\mathrm{mm}] /[\mathrm{cm}]$} & {$[\mathrm{m}]$} & {$[\mathrm{m}]$} & {$[\mathrm{kN} \cdot \mathrm{m}]$} & {$[\mathrm{kN} \cdot \mathrm{m}]$} \\
\hline \multirow{3}{*}{$M L_{60}$} & $\begin{array}{l}A_{S, \min }: \\
\quad \phi 16 / 24\end{array}$ & -20.0 & 0.0 & 186 & - \\
\hline & $A_{S,+}: \quad \phi 12 / 16$ & -17.5 & -12.0 & 337 & - \\
\hline & $A_{S,-}: \quad \phi 10 / 22$ & -11.5 & -5.0 & 263 & - \\
\hline \multirow{3}{*}{$B L_{60+10}$} & $\begin{array}{l}A_{S, \min }: \\
\quad \phi 16 / 24\end{array}$ & -20.0 & 0.0 & 186 & 223 \\
\hline & $A_{S,+}: \quad \phi 10 / 12$ & -17.5 & -12.0 & 326 & - \\
\hline & $A_{S,-}: \quad \phi 10 / 24$ & -11.5 & -5.5 & 257 & 294 \\
\hline \multirow{3}{*}{$B L_{55+10}$} & $\begin{array}{l}A_{S, \min }: \\
\quad \phi 16 / 25\end{array}$ & -20.0 & 0.0 & 161 & 195 \\
\hline & $A_{S,+}: \quad \phi 16 / 28$ & -17.5 & -11.5 & 300 & - \\
\hline & $A_{S,-:} \quad \phi 12 / 28$ & -11.5 & -5.5 & 240 & 275 \\
\hline
\end{tabular}

${ }^{a}$ Anchorage length not included.

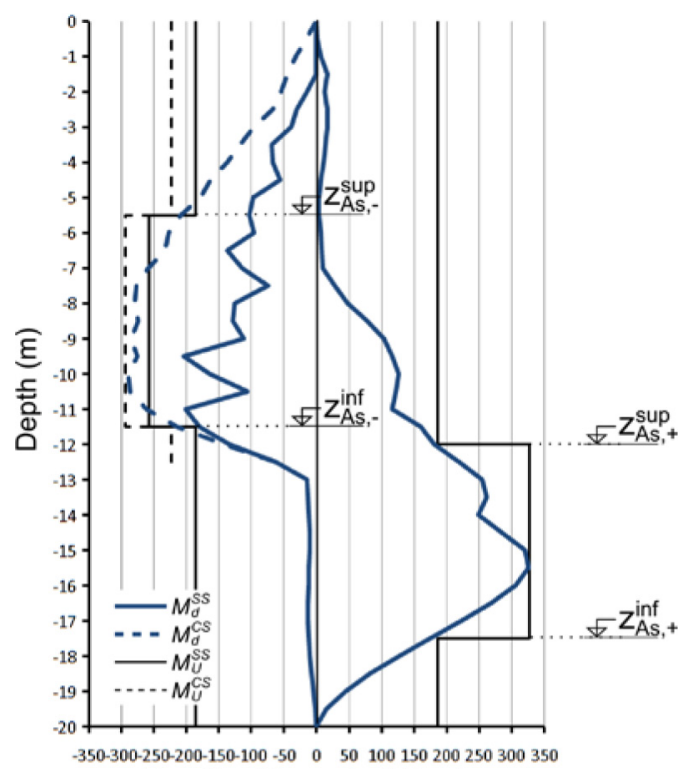

Fig. 7. Ultimate and design moments for the " $B L_{60+10}$ " wall

In the wall types with a $60 \mathrm{~cm}$ thick RC layer, the above percentages are barely superior to the moment increase following the application of the second layer, i.e. the increase in the cross-section resistance, when the SFRC layer is added, is barely higher than the increase in the design moments when the second layer is considered in the structural calculation. In turn, the reduction of the maximum positive moments in the bi-layer wall type also implies a small reduction in the given reinforcements.

As the $B L_{55+10}$ wall type has a thinner cross-section, it requires, on the one hand, a smaller minimum reinforcement but, in the other hand, stronger local reinforcements to carry the design moments, even though these are smaller than in the $B L_{60+10}$ alternative. As an example of design, the ultimate moment resistance for the " $B L_{60+10}$ " wall type is shown in Figure 7. The previ- ously introduced design moments (" $M_{d}$ ") are also shown in the same plot. It can be seen that inequalities of Eqns (1) and (2) are satisfied in every instance.

It can be seen that at depths of between $0.0 \mathrm{~m}$ and $-5.5 \mathrm{~m}$ the wall contains the SFRC layer although it is not strictly necessary, as the resistance of the SS crosssection itself is sufficient to cover the design moments. It would be possible to optimize the use of the fibres, placing them only in the stretches where they are needed for the ultimate resistance of the cross-section. This is, to place the SFRC layer at depths of between $-5.5 \mathrm{~m}$ and $-12.5 \mathrm{~m}$, and to place just sprayed concrete with the waterproofing additive at depths of between $0.0 \mathrm{~m}$ and $-5.5 \mathrm{~m}$ (for waterproofing purposes and to even the surface).

\section{Discussion}

Besides the structural solutions that have been presented, different systems to deal with leakages on diaphragm walls are compared in this section.

Two standard systems aiming to ensure a dry inner wall after building a conventional mono-layer wall are: a) Drained cavity (" $D C$ "): a second inner wall separated from the diaphragm wall. The cavity between them is drained and the water accumulated at the bottom is later pumped out; b) Waterproof mortar layer ("WML"): consists of casting a second layer of waterproof mortar over the inner face of the diaphragm wall. This layer is usually about $5 \mathrm{~cm}$ width, and is cast after the diaphragm wall has been finished, without structural function.

Additionally, an optional modification is added to each of the bi-layer wall types. The Optimized fibres ("Opt.") system utilizes the idea introduced at the end of Section 4, where the fibres are only placed where strictly necessary (i.e. at depths of between $-5.5 \mathrm{~m}$ and $-12.5 \mathrm{~m}$, using a sprayed concrete without fibres for the rest of the spraying layer). The system where fibres are uniformly placed all along the second layer are called "Unif." to differentiate it from the preceding option.

The main differences between these systems are summarised in Table 4. It includes the basic material required for the construction of the complete systems; the maximum displacement registered; the final thickness of the system; and its waterproofing if any.

The different materials are grouped below in accordance with their class. Thus, the volume of the two types of concrete (RC and SFRC) and the mortar used in the "WML" system are grouped under the heading "concrete" and the conventional steel bars used in the RC layer and the steel fibres used in the SFRC layer under "steel". In both cases (concrete and steel), cast and sprayed materials were differentiated. The consumption of extra materials of the " $D C$ " system, as it is of a different class, is not considered in the table. Although the dosages, placing procedures and costs are not the same for the different types of materials, this simplification allows a simple first approach to compare the different systems. 
Table 4. Comparison of different waterproofing systems

\begin{tabular}{|c|c|c|c|c|c|c|c|c|c|}
\hline & & & \multicolumn{3}{|c|}{ Mono-layer } & \multicolumn{4}{|c|}{ Bi-layer } \\
\hline & & & $\mathrm{ML}_{60}$ & $\begin{array}{l}M L_{60}+ \\
D C^{*}\end{array}$ & $\begin{array}{l}M L_{60}+ \\
W M L\end{array}$ & $\begin{array}{l}B L_{60+10}, \\
\text { "Unif." }\end{array}$ & $\begin{array}{l}B L_{55+10} \\
\text { "Unif." }\end{array}$ & $\begin{array}{l}\text { BL } \\
\text { "Opt.10," }\end{array}$ & $\begin{array}{l}\text { BL } L_{55+10} \\
\text { "Opt." }\end{array}$ \\
\hline \multirow{3}{*}{$\begin{array}{l}\text { Concrete } \\
\text { volume }\end{array}$} & Cast layer & $\left(\mathrm{m}^{3} / \mathrm{m}\right)$ & 12.00 & 12.00 & 12.00 & 12.00 & 11.00 & 12.00 & 11.00 \\
\hline & $\begin{array}{l}\text { Sprayed } \\
\text { layer* }\end{array}$ & $\left(\mathrm{m}^{3} / \mathrm{m}\right)$ & - & - & 0.63 & 1.25 & 1.25 & 1.25 & 1.25 \\
\hline & Total & $\left(\mathrm{m}^{3} / \mathrm{m}\right)$ & 12.00 & 12.00 & 12.63 & 13.25 & 12.25 & 13.25 & 12.25 \\
\hline \multirow{3}{*}{ Steel weight } & Cast layer & $(\mathrm{kg} / \mathrm{m})$ & 391 & 391 & 391 & 382 & 381 & 382 & 381 \\
\hline & Sprayed layer & $(\mathrm{kg} / \mathrm{m})$ & - & - & - & 31 & 31 & 18 & 18 \\
\hline & Total & $(\mathrm{kg} / \mathrm{m})$ & 391 & 391 & 391 & 414 & 412 & 400 & 399 \\
\hline \multicolumn{2}{|c|}{ Maximum displacement } & $(\mathrm{mm})$ & -17.3 & -17.3 & -17.3 & -17.6 & -18.1 & -17.6 & -18.1 \\
\hline \multicolumn{2}{|c|}{ Final thickness $^{+}$} & $(\mathrm{cm})$ & & 85 & 65 & 70 & 65 & 70 & 65 \\
\hline \multicolumn{3}{|c|}{ Waterproof system } & $\mathrm{NO}$ & YES & YES & YES & YES & YES & YES \\
\hline
\end{tabular}

* corresponds to the volume of the mortar layer in the " $\mathrm{ML}_{60}+\mathrm{WML}$ " system;

+ the theoretical thickness is considered, without taking accidental deviations into account;

- the consumption of extra materials of a different class is not considered in this system.

With regard to material consumption, the $M L_{60}$ wall type is the one with minor outlay in every material category. Considering that maximum displacements are similar for all systems and that this one, in particular, has the smallest ones, and finally, that this system has the smaller thickness, this system is undoubtedly the most appropriate whenever waterproofness is not required.

The bi-layer wall types achieve a reduction in the $\mathrm{RC}$ layer steel reinforcement. The percentage of reduction in this layer compared with the $M L_{60}$ alternative is, $2.1 \%$ for the $B L_{60+10}$ wall type and $2.5 \%$ for the $B L_{55+10}$ wall type. However, the steel increment in the SFRC layer exceeds the reduction reached in the $\mathrm{RC}$ layer. The percentage increment compared with the $M L_{60}$ wall type is $8.0 \%$ for the "Unif." system, and $4.5 \%$ for the "Opt." bi-layer system. As the material and labour costs per cubic meter of sprayed SFRC are higher than the cost of $\mathrm{RC}$, the structural system of the bi-layer solutions is not favourable in this case.

Comparing the complete systems, including both the structural and the waterproof system, the "Opt." systems are more efficient than the "Unif." systems and will therefore be used in all subsequent comparisons.

The $M L_{60}+D C$ system is nowadays one of the more commonly used for waterproofing the wall surface. The material required for the drained cavity (leaf wall and extraction pump) is assumed to be relatively low. The main drawbacks of this system are: a) Reduced interior space (crucial in the basements of buildings designed for underground parking and other economic activities); b) Need to activate a pump as excess water accumulates; and c) It hides the source and the extent of the leakages, or any other possible structural problem that the walls may have (Puller 1994).

If the use of materials of the $M L_{60}+W M L$ system is compared with the $B L_{60+10}$ ("Opt."), the latter registers an increase of $5.0 \%$ in concrete use and $2.3 \%$ in steel.
Considering that the thickness of the BL system is also larger, the $\mathrm{BL}$ alternative is not favourable in this case.

If the $M L_{60}+W M L$ system is compared with the $B L_{55+10}$ ("Opt."), it should first of all be noted that both have the same final thickness and are also the slenderest of all the waterproof systems under study. Regarding the materials, it can be seen that a reduction of $3.0 \%$ in the amount of concrete (the only material-related value favourable to the bi-layer systems). Finally, an increase in the total amount of steel $(2.0 \%)$ is still registered.

\section{Conclusions}

A design method for the bi-layer diaphragm walls, a new type of slurry wall, has been presented. It allows two levels of comparison, the first of which is based on the structural analysis and the second on the final design, where the comparison includes final material use. The structural behaviour of a conventional ML wall $(60 \mathrm{~cm}$ width $\mathrm{RC}$ layer) has been compared with two BL alternatives $(60 \mathrm{~cm}$ and $55 \mathrm{~cm}$ width RC layer plus $10 \mathrm{~cm}$ width SFRC layer). Furthermore, starting with these wall types, several systems to deal with leakages have been added to the comparison. The main conclusions are summarized in the following points.

There exists a potential of reduction in the reinforcement of the $\mathrm{RC}$ layer of the diaphragm walls through the structural use of the SFRC layer. This potential is measured by the area of moments envelope covered by the simple section $\left(M_{d}^{S S}\right)$. This area is reduced $21 \%$ and $26 \%$ in both $\mathrm{BL}$ alternatives, compared with the $\mathrm{ML}$ wall.

However, it is not possible to take advantage of all this potential in the design process for two reasons that are explained as follows. The increase from the $M_{d}^{S S}$ to the $M_{d}^{C S}$ is, on average, $123 \%$ of the $M_{d}^{C S}$ (at depths of between $-2.5 \mathrm{~m}$ and $-11.0 \mathrm{~m}$ ). Besides, the increase from the $M_{U}^{S S}$ to the $M_{U}^{C S}$ are, in this case, between $15 \%$ and $20 \%$ of the $M_{U}^{C S}$. This means that, if the SS section 
is designed to cover only the SS design moments, the second layer does not provide the additional bending strength to the CS cross-section to cover the moments developed after the second layer is sprayed. Therefore, the SS sections should be designed to cover the $M_{d}^{S S}$ and part of the $M_{d}^{C S}$ moments. The second reason, is that the minimum $M_{U}^{S S}$, given by the minimum reinforcement, already covers a part of the $M_{d}^{C S}$ design moments.

Even though a reduction in the $\mathrm{RC}$ reinforcement is confirmed for both wall types $(2.1 \%$ and $2.5 \%)$, it appears insufficient to compensate for the extra technologies and consumption of materials to build the bi-layer solutions. Nonetheless, the complete waterproof system becomes an interesting solution when particular conditions are taken into account, such as basement space limitations or if continuous maintenance wants to be avoided.

Future work should include a parametric study to evaluate, by means of the two level comparison presented in this study, the influence of the general condition and wall design on the profitability of the bi-layer wall type.

\section{Acknowledgements}

Funding was made available from the Spanish Ministry of Education and Science through Research Project BIA2010-17478: Procesos constructivos mediante hormigones reforzados con fibras. Luis Segura-Castillo is grateful for the Fellowship awarded by the FPU Spanish Research Program (AP2010-3789).

\section{References}

Brinkgreve, R. 2002. PLAXIS 2D, Version 8. Lisse: A.A. Balkema Publishers.

Bryson, L. S.; Zapata-Medina, D. G. 2012. Method for estimating system stiffness for excavation support walls, Journal of Geotechnical and Geoenvironmental Engineering 138(9): 1104-1115.

http://dx.doi.org/10.1061/(ASCE)GT.1943-5606.0000683

Carrubba, P.; Colonna, P. 2000. A comparison of numerical methods for multi-tied walls, Computers and Geotechnics 27: 117-140.

http://dx.doi.org/10.1016/S0266-352X(00)00007-0

Costa, P. A.; Borges, J. L.; Fernandes, M. M. 2007. Analysis of a braced excavation in soft soils considering the consolidation effect, Geotechnical and Geological Engineering 25(6): 617-629.

http://dx.doi.org/10.1007/s10706-007-9134-7

CPH. 2008. EHE-08: Instrucción del Hormigón Estructural.

de la Fuente, A.; Aguado, A.; Molins, C.; Armengou, J. 2012a. Numerical model for the analysis up to failure of precast concrete sections, Computers \& Structures 106-107: 105-114.

http://dx.doi.org/10.1016/j.compstruc.2012.04.007

de la Fuente, A.; Escariz, R. C.; Figueiredo, A. D.; Molins, C.; Aguado, A. 2012b. A new design method for steel fibre reinforced concrete pipes, Construction and Building
Materials 30: 547-555.

http://dx.doi.org/10.1016/j.conbuildmat.2011.12.015

BS EN 1992-1-1: 2004. Eurocode 2: Design of concrete structures - Part 1: general rules and rules for buildings. Brussels: European Committee for Standardization, Belgium, 2004.

Hashash, Y. M. A.; Levasseur, S.; Osouli, A.; Finno, R.; Malecot, Y. 2010. Comparison of two inverse analysis techniques for learning deep excavation response, Computers and Geotechnics 37(3): 323-333. http://dx.doi.org/10.1016/j.compgeo.2009.11.005

Hsiung, B. C. B. 2009. A case study on the behaviour of a deep excavation in sand, Computers and Geotechnics 36(4): 665-675.

http://dx.doi.org/10.1016/j.compgeo.2008.10.003

Khoiri, M.; Ou, C. Y. 2013. Evaluation of deformation parameter for deep excavation in sand through case histories, Computers and Geotechnics 47: 57-67.

http://dx.doi.org/10.1016/j.compgeo.2012.06.009

Kung, G. T. C.; Juang, C. H.; Hsiao, E. C. L.; Hashash, Y. M. A. 2007. Simplified model for wall deflection and groundsurface settlement caused by braced excavation in clays, Journal of Geotechnical and Geoenvironmental Engineering 133(6): 731-747.

http://dx.doi.org/10.1061/(ASCE)1090-0241(2007)133:6(731)

Kung, G. T. C. 2009. Comparison of excavation-induced wall deflection using top-down and bottom-up construction methods in Taipei silty clay, Computers and Geotechnics 36(3): 373-385.

http://dx.doi.org/10.1016/j.compgeo.2008.07.001

Long, M. 2001. Database for retaining wall and ground movements due to deep excavations, Journal of Geotechnical and Geoenvironmental Engineering 127(3): 203-224.

http://dx.doi.org/10.1061/(ASCE)1090-0241(2001)127:3(203)

Ou, C. Y.; Lai, C. H. 1994. Finite-element analysis of deep excavation in layered sandy and clayey soil deposits, Canadian Geotechnical Journal 31: 204-214. http://dx.doi.org/10.1139/t94-026

PLAXIS 2D - Tutorial Manual. 2010 [online], [cited 1 December 2011]. Available from Internet:

http://www.plaxis.n1/files/files/2D2010-2-Reference_02.pdf

Puller, M. 1994. The waterproofness of structural diaphragm walls, in Proceedings of the ICE - Geotechnical Engineering 107(1): 47-57. http://dx.doi.org/10.1680/igeng.1994.25720

RILEM TC 162-TDF. 2003. Test and design methods for steel fibre reinforced concrete, Materials and Structures 36(October): 560-567.

Schanz, T.; Vermeer, P. A.; Bonnier, P. G. 1999. The hardening soil model: formulation and verification. Beyond 2000 in computational geotechnics - 10 years of PLAXIS. Rotterdam: Balkema, 1-16.

Segura-Castillo, L.; Aguado, A.; Josa, A. 2013. Bi-layer diaphragm walls: experimental and numerical structural analysis, Engineering Structures 56: 154-164. http://dx.doi.org/10.1016/j.engstruct.2013.04.018

Segura-Castillo, L.; Aguado A. 2012. Bi-layer diaphragm walls: Evolution of concrete-to-concrete bond strength at early ages, Construction \& Building Materials 31: 29-37. http://dx.doi.org/10.1016/j.conbuildmat.2011.12.090

Terzaghi, K.; Peck, R. B.; Mesri, G. 1996. Soil mechanics in engineering practice. New York: John Wiley \& Sons. 592 p. 
Luis SEGURA-CASTILLO. Assistant Professor of the Structures and Transportation Institute at the University of the Republic (Uruguay). $\mathrm{PhD}$ candidate at the Department of Construction Engineering at the Universitat Politècnica de Catalunya. His major research interests include behaviour and design of structural elements and sprayed and fibre reinforced concrete.

Antonio AGUADO. Professor. Department of Construction Engineering. BarcelonaTech. Spain. His main research interests are specials concrete and technology, concrete dams and tunnels, sustainability, multicriteria analysis for integral and objective evaluation.

Albert de la FUENTE ANTEQUERA. He is a Lecturer Professor in the field of Concrete Structures of the Departament d'Enginyeria de la Construcció at Universitat Politècnica de Catalunya. His main research interests include nonlinear analysis of concrete structures, optimization of fiber reinforced structures and its industrial applications and life cycle assessment (LCA).

Alejandro JOSA. Professor of the Department of Geotechnical Engineering and Geosciences at the Universitat Politecnica de Catalunya, Barcelona, Spain. His main research interests are the LCA of different construction applications, the quantitative assessment of sustainability, the mechanical modelling of soils and the behaviour of geotechnical structures. 